\title{
COGNITIVE FUNCTION ASSESSMENT IN IDIOPATHIC PARKINSON'S DISEASE
}

\author{
Mauro R. Piovezan, Helio A.G. Teive, Elcio J. Piovesan, \\ Maria J. Mader, Lineu Cesar Werneck.
}

\begin{abstract}
Idiopathic Parkinson's disease (PD) is characterized by reduced nigrostriatal and cortical dopaminergic influence, with changes in movement and, subsequently, behavioral and cognitive disturbances. We studied cognitive impairment in Parkinson's disease by assessing a group of 30 idiopathic Parkinson's disease patients with an average age of 64.23 years (PG group) and compared our findings with those for a control group of 30 patients (CG group). All the patients were submitted to the following assessments: motor function, using the UPDRS; staging, using the Hoehn-Yahr scales (PG group only); depression, using the Montgomery-Asberg scale; attention impairment; verbal fluency (FAR and animals); cognitive function, using the Mini Mental State Examination; visuospatial and executive functions; and clock drawing. In addition to altered motor function in PD patients, we found statistically significant differences between PD patients and controls in terms of cognitive function, verbal, executive and visuospatial functions, and attention deficits. Depression was more prevalent in the PG group.
\end{abstract}

KEY WORS: depression, idiopathic Parkinson's disease, cognitive function.

\begin{abstract}
Avaliação da função cognitiva em doença de Parkinson idiopática
RESUMO - A doença de Parkinson idiopática (DP) caracteriza-se pela redução da influência dopaminérgica nigroestriatal e cortical, com alterações em movimentos e posteriormente, comportamentais e cognitivas. Estudamos o comprometimento cognitivo de pacientes portadores de DP, avaliando 30 pacientes com doença de Parkinson idiopática (GP) com média de idade de 64,23 anos e os comparamos com um grupo controle (GC) de 30 pacientes. Todos os pacientes foram submetidos as seguintes avaliações: motora pela escala de UPDRS; estadiamento pela escala de Hoehn-Yahr (somente GP); depressão pela escala de Montgomery-Asberg; comprometimento da atenção; fluência verbal (FAR e animais); função cognitiva pelo Mini Exame do Estado Mental; funções visuoespaciais e executivas e desenho do relógio. Concluímos que na DP os pacientes apresentam além das alterações motoras diferenças estatisticamente significativas a nível cognitivo, na função verbal, funções executivas, visuoespaciais e distúrbios de atenção. Depressão foi mais prevalente no GP.
\end{abstract}

PALAVRAS-CHAVE: depressão, doença de Parkinson idiopática, função cognitiva.

Although the original description by James Parkinson ${ }^{1}$ did not consider cognitive disturbances to be an integral part of the symptomatology of Parkinson's disease (PD), but Charcot and Vulpian ${ }^{2,3}$ describe such disturbances for the first time, and their findings were confirmed in recent studies ${ }^{4,5}$. Postmortem neuropathological studies and the use of in vivo PET scans show that nigrostriatal dopaminergic neuronal degeneration is the main physiopathological mechanism in Parkinson's disease ${ }^{5,6}$. The nigrostriatal dopaminergic system is part of one of the five frontostriatal circuits ${ }^{7}$. Disruption of dopaminergic influence in these circuits has consequences for other circuits and thus explains a number of cognitive symptoma- tologies. Dopaminergic dysfunction produces cognitive symptomatology similar to that found in individuals with frontal lesions ${ }^{8,9}$. Cognitive deficits mainly affect memory mechanisms and visuospatial and executive functions $s^{4,6,9,10}$. Other neurochemical circuits, such as the serotoninergic, noradrenergic and cholinergic circuits, are also affected in PD and contribute to cognitive dysfunction ${ }^{5,6,9,10}$. As well as causing impairment of cognitive function, serotoninergic alterations can also cause an increased prevalence of depression in PD sufferers ${ }^{9,11-13}$. Patients with PD and depression have more severe cognitive deficits than those with PD but without depression; such deficits are found mainly in the executive functions ${ }^{14}$.

Neurology Division, Internal Medicine Department, Hospital de Clinicas, Universidade Federal do Paraná, Curitiba PR, Brazil.

Received 15 May 2007. Accepted 28 August 2007.

Dr. Lineu Cesar Werneck - Serviço de Neurologia / Hospital de Clínicas da UFPR - Rua General Carneiro 181 / $12^{\circ}$ andar / Sala 1236 8006o-goo Curitiba PR - Brasil. E-mail: werneck@hc.ufpr.br 
Cognitive disturbances can occur during any stage of PD. During the very early stages of the disease, these may not be clinically apparent and may only be detected by special neuropsychological tests ${ }^{5}$. The exact pattern and frequency of these deficits is still the subject of some controversy ${ }^{3}$.

The aim of this study was to assess cognitive deficits in PD by using various cognitive assessment methods and comparing the results for a group of PD patients with those for a control group of normal individuals.

\section{METHOD}

We studied the cognitive function in 60 individuals paired by age, sex and education. Thirty of them were idiopathic Parkinson's disease (IPD) sufferers (referred to as the Parkinson, or PG group) and had an average age of 64.23 11.24 years. The other 30 individuals (referred to as the control, or CG group) were asymptomatic, with an average age of $64.13 \pm 1.27$ years. In each group, $43.33 \%$ of the individuals were male.

Data relating to age, sex and education are shown in Table 1.

The PG group was divided into two subgroups: PG with depression (PWID) $(n=7)$ and PG without depression (PWOD) $(n=23)$. Three controls had scores that were indicative of de- pression and were therefore excluded from the study. None of the patients in the PWID group were taking medication with a potential anti-cholinergic effect.

Patients in the PG group were recruited from the Movement Disorders Outpatient Unit in the Neurology Division, Hospital de Clínicas, Universidade Federal do Paraná. The controls were recruited from the community.

The London Brain Bank diagnostic criteria for idiopathic Parkinson's disease (bradykinesia, rigidity, tremor, postural instability, asymmetry and a positive response to levodopa) were used to include patients in the PG group; members of the control group could not have any of the diagnostic criteria for IPD or signs of parkinsonism ${ }^{15}$. The exclusion criteria for the PG group were other forms of parkinsonism (atypical forms, also known as Parkinson-plus syndromes, or secondary or heterodegenerative forms) pallidotomy, thalamotomy or the presence of diagnostic criteria for dementia as defined in the DSM IV ${ }^{16}$.

The patients from both the PG and CG groups were submitted to anamnesis and a general physical and neurological examination. Thyroid function tests and computerized brain tomography for the PG group were assessed retrospectively using information from the patients' medical records. Only the patients in the PG group were submitted to motor assessment using the UPDRS scale ${ }^{17}$ and severity of Parkinson's disease using Hoehn-Yahr staging ${ }^{18}$.

Table 1. Descriptive data for the Parkinson and control groups.

\begin{tabular}{lcc}
\hline Variables & Parkinson group & Control group \\
\hline Age & $64.23 \pm 11.24$ & $64.13 \pm 11.27$ \\
Sex & & $43.33 \%(n=13)$ \\
$\quad$ Male & $43.33 \%(n=13)$ & $56,67 \%(n=17)$ \\
$\quad$ Female & $56.67 \%(n=17)$ & \\
Level of education & & \\
$\quad$ Illiterate & $10 \%(n=3)$ & $10 \%(n=3)$ \\
$1^{\text {st }}$ grade to $4^{\text {th }}$ grade & $73.33 \%(n=22)$ & $73.33 \%(n=22)$ \\
$5^{\text {th }}$ grade to $8^{\text {th }}$ grade & $10 \%(n=3)$ & $10 \%(n=3)$ \\
Secondary school & $3.33 \%(n=1)$ & $3.33 \%(n=1)$ \\
Technical college & $3.33(n=1)$ & $3.33 \%(n=1)$ \\
UPDRS & $21.43 \pm 7.20$ & - \\
HOENH-YAHR & $2.43 \pm 0.92$ & - \\
\hline
\end{tabular}

Table 2. Descriptive analysis of the cognitive tests for Parkinson and control groups.

\begin{tabular}{|c|c|c|c|c|c|c|c|}
\hline \multirow[t]{2}{*}{ Variable } & \multicolumn{3}{|c|}{ Parkinson group $(n=30)$} & \multicolumn{3}{|c|}{ Control group $(n=30)$} & \multirow[t]{2}{*}{$P$ value* } \\
\hline & Median & Range & Average (SD) & Median & Range & Average $\pm S D$ & \\
\hline MADRS & 12 & $4-28$ & $12.80 \pm 6.86$ & 4 & $0-22$ & $6.27 \pm 6.45$ & 0,0013 \\
\hline MMSE & 24 & $10-30$ & $23.10 \pm 4.89$ & 28 & $23-30$ & $27.80 \pm 2.01$ & 0,0001 \\
\hline FAR & 15 & $0-47$ & $15.40 \pm 11.06$ & 20 & $4-53$ & $23.50 \pm 11.15$ & 0.0093 \\
\hline Animals & 9 & $1-20$ & $9.43 \pm 4.25$ & 12 & $0-16$ & $11.97 \pm 3.01$ & 0.0121 \\
\hline Mistakes (attention) & 1 & $0-52$ & $4.83 \pm 10.11$ & 0 & $0-11$ & $0.53 \pm 2.03$ & 0.0003 \\
\hline Clock & 6 & $0-10$ & $6.07 \pm 2.99$ & 10 & $2-10$ & $8.97 \pm 1.88$ & 0.0002 \\
\hline House & 5 & $0-5$ & $4.17 \pm 1.26$ & 5 & 4-5 & $4.97 \pm 0.18$ & 0.0015 \\
\hline
\end{tabular}


Table 3. Correlation between degree of incapacity and staging using cognitive tests in Parkinson's patients.

\begin{tabular}{llcc}
\hline Variable & Variable & Spearman correlation & P value \\
\hline HOEHN-YAHR & MADRS & 0.5056 & 0.0044 \\
MADRS & UPDRS & 0.5966 & 0.0005 \\
& Clock & -0.3615 & 0.0497 \\
MMSE & UPDRS & 0.5865 & 0.0007 \\
& FAR & 0.7820 & $<0.0001$ \\
FAR & Clock & 0.7134 & $<0.0001$ \\
& Mistakes (attention) & -0.3884 & 0.0339 \\
Mistakes (attention) & Clock & 0.6162 & 0.0003 \\
Clock & Clock & -0.4118 & 0.0237 \\
\hline
\end{tabular}

$N B$, only those values that are statistically significant $(p<0.05)$ are shown.

Both groups were submitted to: 1) Assessment of depression using the Montgomery-Asberg Depression Rating Scale (MADRS) $^{19,20}$, with a value of 17 points on this scale being used to diagnose depression; 2) Assessment of attention by means of sequences of numbers in numerical order (numbers from 01 to 20), alternating sequences (4 6810121416 $1820-36912151821242730$ ) and reverse sequences (repeating days of the week and months of the year in numerical and reverse order $)^{21}$; 3) Assessment of verbal functions by evaluating verbal fluency using FAR (phoneme fluency) and animal (category fluency) tests, in which the subject is asked to produce as many words starting with the letters $F$, $A$ and $R$ and to name as many animals as possible in 60 seconds ${ }^{22}$; 4) Assessment of global cognitive state by means of the mini mental state examination (MMSE) ${ }^{23} ; 5$ ) Assessment of visuospatial functions by copying a drawing of a house and of a clock ${ }^{24,25}$

Thyroid function tests for the PG group were reviewed using the patients' medical records and revealed normal thyroid hormone serum levels. Only 15 patients (in the PG group) underwent computerized brain tomography; one patient was found to have calcification in the left thalamus and the other, a right subinsular lacunar infarct. As test scores for these patients were normal, the possibility that these lesions might have influenced the results of the tests was eliminated.

This study was approved by the Human Research Ethics Committee of the Hospital de Clínicas, Federal University of Paraná. All those who took part in the study signed a voluntary informed-consent form after they had been told about the aims of the study and the tests they would be submitted to.

The descriptive results were expressed as averages together with their respective standard deviations and maximum and minimum values. The Wilcoxon nonparametric test was used to compare the groups, and the Spearman correlation coefficients were estimated to identify whether there was any association between the variables. Student's t-test was used to compare the PG subgroups and CG group. A value of $\mathrm{p}<0.05$ was considered statistically significant in all the tests.
Table 4. Cognitive tests in patients with Parkinson's disease and controls.

\begin{tabular}{lccc}
\hline & CG $\times$ PWOD & CG $\times$ PWID & PWOD $\times$ PWID \\
\hline MADRS & $\mathrm{p}<0.0001$ & $\mathrm{p}<0.0001$ & $\mathrm{p}<0.0001$ \\
MMSE & $\mathrm{p}<0.0001$ & $\mathrm{p}<0.0001$ & $\mathrm{p}=0.1000$ \\
FAR & $\mathrm{p}=0.05$ & $\mathrm{p}=0.022$ & $\mathrm{p}=0.304$ \\
Animals & $\mathrm{p}=0.23$ & $\mathrm{p}<0.0001$ & $\mathrm{p}<0.008$ \\
Mistakes* & $\mathrm{p}=0.009$ & $\mathrm{p}=0.032$ & $\mathrm{p}=0.25$ \\
House & $\mathrm{p}=0.003$ & $\mathrm{p}<0.0001$ & $\mathrm{p}=0.07$ \\
Clock & $\mathrm{p}=0.001$ & $\mathrm{p}<0.0001$ & $\mathrm{p}=0.22$ \\
\hline
\end{tabular}

*mistakes attention; CG, control group; PWOD, Parkinson group without depression; PWID, Parkinson group with depression.

\section{RESULTS}

The average time from the appearance of the symptoms to the time when the tests were performed was $7.33 \pm 4.76$ years. The average score on the UPDRS motor examination scale was $21.43 \pm 7.20$ and on the (modified) Hoehn-Yahr staging scale $2.43 \pm 0.92$ (Table 1).

The differences between the scores for the PG group and those for the CG group were statistically significant in all the tests (Table 2).

The severity of IPD was directly related to the patient's degree of depression, as can be seen by the direct correlation between the Hoehn-Yahr scale and MADRS. The greater the depressive symptomatology, the poorer the performance in executive functions, as shown by the inverse correlation between MADRS and the clock-drawing test; and the greater the MADRS score, the greater the motor deficiency in the PG group, as shown by the direct correlation with UPDRS score $(p=0.0007)$. The greater the MMSE score, the greater the performance in the verbal functions, as evidenced by the direct correlation between MMSE, FAR and the clock-drawing test. An inverse 
correlation was found between verbal function and the attention test (in other words, the greater the impairment of verbal function, the poorer the performance in the attention test) and a direct correlation between verbal function and the clock-drawing test. We observed an inverse correlation between the attention test and the clock-drawing test and a direct correlation between the latter test and the housedrawing test (Table 3). The statistical analysis of the results for the PG subgroups and the CG group are shown in Table 4. There was a statistically significant correlation between the time for PD to evolve and the MADRS score $(p=0.009)$.

\section{DISCUSSION}

Our findings showed that there was a statistically significant difference between the results of the following tests in the neuropsychological test battery for the PG and the CG groups: MADRS, MMSE, attentions tests, verbal fluency and executive and visuospatial functions.

Menza and Mark showed that there was a greater prevalence of depressive symptomatology in IPD than in healthy individuals ${ }^{26}$. According to Cummings, patients with PD and depression perform worse in various tests mediated by the frontal lobes ${ }^{13}$.

Leentjens et al. found that both the Hamilton scale (HAMD) and the Montgomery-Asberg scale (MADRS) are suitable instruments for diagnosing pictures of depression in $\mathrm{PD}^{20}$.

We showed that depressive symptomatology was more prevalent in the PG group than in the CG group. Furthermore, our finding of a relationship between executive deficits (particularly in the clock-drawing test) and the severity of the disease is an important one. However, comparison of individuals with and without depression did not reveal any statistically significant data that indicated that depression could have an influence on cognitive function in this group. Nevertheless, when the PG group with depression and the CG group without depression were compared, greater cognitive impairment was observed in the former group, particularly in tests measuring executive functions. This finding was also reported by Starkstein et al. ${ }^{27}$. We found that the results of the category verbal fluency tests (animals) for the PG group with depression were poorer than those for the PG group without depression and the CG group, clearly showing that depression affects the results of this cognitive test. When evaluating only the executive functions, the results for the animal test (and not those for the house or FAR tests) differed from the controls. According to Lezak et al., this is explained by the greater difficulty PD sufferers have with category verbal fluency than with phonetic verbal fluency ${ }^{21}$.

We did not find a statistically significant correlation between the MADRS scale and phonemic or category verbal fluency tests but only found such a correlation with the clock-drawing test. Thus, our findings with regard to verbal fluency tests did not confirm

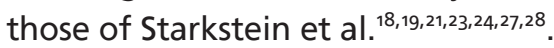

The PG group as a whole, rather than just those individuals whose scores indicated that they were depressive, had more obvious cognitive deficits than the CG group, contrary to the findings of Starkstein et al., who stated that patients with major depression would have greater cognitive impairments than those with less severe depression ${ }^{27}$.

According to the literature, there is an interaction between the severity of the disease and the presence of depression. Depressed patients with severe IPD had greater neuropsychological impairments, particularly in executive function tests ${ }^{13}$. In the present study, we were able to show a relationship between the results on the Hoehn-Yahr and MADRS scales. The results in the clock-drawing test were borderline and not statistically significant.

The tasks used to assess executive functions included the verbal fluency and clock-drawing tests ${ }^{22,24,25}$. The results of this study corroborate the findings in the literature and show that verbal fluency and performance of the clock-drawing test, which are involved in the assessment of executive functions, are altered compared with the performance of the same tasks by the CG group, thus confirming the findings reported by Dubois and Pillon ${ }^{29}$.

A correlation was also identified between the phonetic verbal fluency test and the MMSE and attention tests, showing the influence of attentional processes on cognitive deficits in IPD. According to Hassler, the striatum is of fundamental importance in attentional processes ${ }^{30}$. Ivory et al. suggest that memory deficits in IPD may be partly explained by executive function deficits related to the frontal dysfunction found in this disease ${ }^{31}$.

No correlation was found between executive deficits and Hoehn-Yahr and UPDRS scores, indicating that these deficits are part of a broader cognitive decline or that they may be restricted to a subgroup of patients and/or did not occur in the initial stages of the disease in the group studied ${ }^{32,33}$. 
Visuospatial deficits in IPD patients remain the subject of some discussion because of the discrepancy in the data from the various studies that have investigated these deficits. This may be because a number of different cognitive tasks with different mechanisms have been grouped together as visuospatial functions. We have shown that there were statistically significant differences between the two groups, although no correlation between UPDRS and HoehnYahr scores was observed, i.e., no correlation with severity of the disease, as previously reported ${ }^{34}$. The relationship between visuospatial and executive functions as a result of frontal impairment in IPD could be explained in this study by the correlation with the clock-drawing test.

We conclude that IPD sufferers have greater cognitive impairment in all the neuropsychological tests carried out than do the control group and that this can be most readily seen in the tasks that assess executive functions. It appears that the frontal dysfunction triggered by PD plays a fundamental role in the genesis of cognitive changes.

\section{REFERENCES}

1. Parkinson J. On essay on the shaking palsy. London Sherwood: Nelly \& Jones; 1887.

2. Charcot JM, Vulpian A. De la paralysie agitante. Gazette Hebdomadaine de Médicine et de Chirurgia, 1861;8:765-767.

3. Lees AJ, Smith E. Cognitive deficits in the early stages of Parkinson's disease. Brains J Neurol 1983;106:257-270.

4. Brown RG, Marsden CD. Cognitive functions in Parkinson's disease: from description to theory. Trends Neurosci 1990;13:21-29.

5. Dubois B, Pillon B. Cognitive deficits in Parkinson's disease. J Neurol 1997;244:2-248.

6. Emre M. What causes mental dysfunction in Parkinson's disease? Mov Disord 2003;18(Suppl):S63-S71.

7. Alexander GE, De Long MR, Strick PL. Parallel organizations of functionally segregated circuits linking basal ganglia and cortex. Annu Rev Neurosci 1986;9:357-381.

8. Agid Y, Javoy-Agid F, Ruberg M. Biochemistry of neurotransmitters in Parkinson's disease. In: Marsden CD, Fahn S (Eds). Movement disorders 2. Neurology, vol 7. London: Buterworths, 1987:166-230.

9. Zgaljardic DJ, Foldi NS, Borod JC. Cognitive and behavioral dysfunction in Parkinson's disease: neurochemical and clinicopathological contributions. J Neural Transm 2004;11:1287-1301.

10. Owen AM. Cognitive dysfunctions in Parkinson's disease: the role of frontostriatal circuitry. The Neuroscientist 2004:10:525-537.

11. Starkstein, Mayberg HS, Preziosi TJ, Robinson RG. A prospective longitudinal study of depression. Cognitive decline and physical impair- ments in patients with Parkinson's disease. J Neurol Neurosurg Psychiatry 1992;55:377-382.

12. Burn DJ. Depression in Parkinson's disease. Eur J Neurology 2002;9(Suppl 3):S44-S54

13. Cummings JL. Depression and Parkinson's disease: a review. Am J Psychiatry 1992;149:443-454.

14. Taylor AE, Saint-Cyr JA. Depression in Parkinson's disease: reconciling physiological and psychological perspectives. J Neuropsychiatr Clin Neurosci 1990;2:92-98.

15. Hughes AJ, Daniel SE, Kilford L, Lees AJ. Accuracy of clinical diagnosis of idiophatic Parkinson's disease: a clinico-pathological study of 100 cases. J Neurol Neurosurg Psychiatry 1992;55:100-1013.

16. American Psychiatric Association. Diagnostic and Statistical Manual of Mental Disorders (DSM IV). Washington, DC: Masson Ed, 1995.

17. Fahn S, Elton RL. Members of the UPDRS Development Committee. Unified Parkinson's disease rating scale. In: Fahn S, Marsden CD, Calne DB, Golsteins M (eds). Recent developments in Parkinson's disease, vol 2, Florham Park, NJ, Macmillan Health Care Informations, 1987:153-164.

18. Hoehn MM, Yahr MD. Parkinsonism: onset, progression and mortality. Neurology 1967;17:427-442.

19. Montgomery SA, Asberg M. A new depression scale designed to be sensitive to change. Br J Psychiatry 1979;134:382-389.

20. Leentjens AF, Verhe FR, Lousberg R, Spitsgergen H, Wilmink FW. The validity of the Hamilton and Montgomery-Asberg depression rating scales as screening and diagnostic tools for depression in Parkinson's disease. Int J Geriatr Psychiatry 2000;15:6440-6449.

21. Lezak MD, Howieson DB, Loring DW. Neuropsychological assesment:Oxford University Press, 2004.

22. Benton AL, Hamsher KS. Multilingual aphasia examinations. Iowa City: AJA Associates; 1989.

23. Folsteins MH, Folsteins SE, McHugh PR. Mini Mental State. A practical method for grading the cognitive state of patients for the clinician. J Psychiatr Res 1975;12:189-198.

24. Spreen O, Strauss E. A compendium of neuropsychological tests. New York: Oxford University Press, 1991.

25. Spreen O, Strauss E. A compendium of neuropsychological tests (2.Ed.) New York: Oxford University Press, 1998.

26. Menza MA, Mark MH. Parkinson's disease and depression: the relationship to disability and personality. J Neuropsychiatr Clin Neurosci 1994;6:165-169.

27. Starkstein SE, Merello M. Psychiatry and cognitive disorders in Parkinson's disease. Cambridge University Press 2002;88-113.

28. Kuzis G, Sabe L, Tiberti C, Leiguarda R, Starkstein SE. Cognitive functions in major depression and Parkinson's disease. Arch Neurol 1997;54: 982-986.

29. Dubois B, Pillon B. Cognitive deficits in Parkinson's disease. J Neurol 1997;244:2-8.

30. Hassler R. Striatal control of locomotion, intentional actions and of integrating and perceptive activity. J Neurol Sci 1978,36:186-224.

31. Ivory SJ, Knight RG, Longmore BE, Caradoc-Davies T. Verbal memory in non-demented patients with idiopathic Parkinson's disease. Neuropsychologia 1999;37:817-828.

32. Graham JM, Sagar HJ. A data-driven approach to the study of heterogenity in idiopathic Parkinson's disease: identification of three distinct subtypes. Mov Disord 1999;14:10-20.

33. Mohr E, Juncos J, Cox C, Litvan I, Fedio P, Chase TN. Selective deficits in cognition and memory in high-functioning Parkinsonian patients. J Neurol Neurosurg Psychiatry 1990;53:603-606.

34. Crucian GP, Barret AM, Schwartz RL. Cognitive and vestibulo-proprioceptive components of ability in Parkinson's disease. Neuropsychologia 1999;38:757-767. 